\title{
Dysfunctional Behavior at the Workplace and Its Impact on Employees' Job Performance
}

\author{
Omar Ramzy ${ }^{1}$, Randa El Bedawy² \& Aya Maher $^{3}$ \\ ${ }^{1}$ Faculty of Business \& Economics, Heliopolis University for Sustainable Development, Egypt \\ ${ }^{2}$ Faculty of Business Administration and International Trade, Misr International University, Egypt \\ ${ }^{3}$ American University in Cairo, Egypt \\ Correspondence: Omar Ramzy, Faculty of Business \& Economics, Heliopolis University for Sustainable \\ Development, Egypt.
}

Received: July 11, 2018

Accepted: July 19, 2018

Online Published: July 30, 2018

doi:10.5430/ijba.v9n4p224

URL: https://doi.org/10.5430/ijba.v9n4p224

\begin{abstract}
Dysfunctional behavior at the workplace reflects the behavior that violates remarkably the accepted norms at the workplace which is in turn can be destructive to overall organizational performance. This study aims to explore the relationship between dysfunctional behavior at the workplace and employees' job performance. In order to study the issue of organizational dysfunction in Egypt, a unique organization was taken as a case study, namely SEKEM. This research is qualitative research based on the approach of Action Research. Through this approach, a semi-structured interview was designed by the researchers and used to collect data from the employees of SEKEM. As such, it is recommended to take new approaches to effectively manage dysfunctional behavior at the workplace.
\end{abstract}

Keywords: dysfunctional behavior, human resource management, organizational behavior, job performance

\section{Introduction}

Dysfunctional behavior refers to the discretionary behavior that tends to be damaging generally to the organization as well as its members. Peterson (2002) defines dysfunctional behavior as the behavior that intends to violate appropriate norms and policies at the workplace, which in turn can damage the overall organizational performance. Unfortunately, several studies shed the light that there is a remarkable growth of dysfunctional behavior at the workplace such as sexual harassment, lying, and bullying (Gill, Meyer, Lee, Shin, \& Yoon, 2011; Reid \& Ramarajan, 2016). There are other various forms of dysfunctional behavior such as theft, arrogance, alcohol consumption, extending the breaks time periods, and many other forms as well (Esfahani \& Shahbazi, 2014). Dysfunctional behavior at workplace affects negatively the overall organization performance such leading to declining productivity, increasing job dissatisfaction, higher turnover, and higher levels of work-related stress, which in turn can damage the overall organizational performance. Accordingly, dysfunctional behavior at the workplace can negatively affect the employees' personal and professional well-being as well as being a significant cost on the organization (Cleary, Walter, Andrew, \& Jackson, 2013; Reid \& Ramarajan, 2016; van Fleet \& van Fleet, 2012).

\section{Literature Review}

\subsection{Dysfunctional Behavior: Concept and Types}

According to (Balthazard, Cooke, \& Potter, 2006), dysfunctional behavior at workplace refers to the deviant behavior that negatively affects employees, suppliers, customers which is reflected on the overall organizational performance. According to (Peterson, 2002), dysfunctional behavior refers to conducts that violate work code of ethics and regulations which can negatively affect work relations and the overall performance inside organizations. Accordingly, dysfunctional behavior at the workplace is considered a serious problem that should require both the awareness of management, as well as the implementation of the proper procedures for tackling such sources of dysfunction; otherwise it will reflect negatively on the overall organizational performance (MacKenzie, Garavan, \& Carbery, 2015; van Fleet \& van Fleet, 2012).

According to Gill et al. (2011), employees in different organizations can participate in various forms of dysfunctional behavior. Various studies shed light on the various forms of dysfunctional behavior at the workplace which can 
include even extreme deviant behavior such as theft, fraud, sexual harassment, and destroying the property of the company. Moreover, it can be sometimes categorized as unethical behaviors such as being aggressive, spreading gossips, lying, jealousy, withholding effort, or even being absence without a valid justification (Salin, 2015).

Dysfunctional behavior can usually be found in organizations that allow lack of fairness and lack of transparency which force the employees to feel humiliation and lack of equity. Moreover, a major reason leading to dysfunctional behavior at work place can be related to the spread of corruption and favoritism, adding to the absence of code of ethics and management's failure to respond directly and to take corrective action towards dysfunctional behavior (Shabrawy \& Afifi, 2014). According to (Caruana, Ramaseshan, \& Ewing, 2001), there are various factors that may trigger dysfunctional behavior such as lack of equity, lack of proper formalizations, inappropriate organizational culture, lack of proper supervisor's behavior to control the organization behavior (Henle, 2005; MacKenzie et al., 2015; Salin, 2015).

Various studies shed light on the most common types of dysfunctional behaviors that can grow quickly such as bullying, violence, and harassment. It is crucial to combat the dysfunctional behavior because it affects the overall organizational performance, which in turn can damage the organization's image and reputation (Esfahani \& Shahbazi, 2014).

\subsubsection{Bullying as Dysfunctional Behavior}

Bullying refers to the severe mistreatment of a colleague or coworker that may affect the person's health, career, and even hurt their social relationships. In other words, it can destroy the person's profile. Bullying in the workplace can be an offensive, unwelcome, or very aggressive verbal communication; it can also include aggressive behavior such as intimidation or sexual harassment at the workplace (Rousseau, Eddleston, Patel, \& Kellermanns, 2014). According to (Branch, Ramsay, \& Barker, 2013), bullying in the workplace refers to a situation when a person is exposed to being mistreated by others through a long period of time through methods including humiliation, yelling, or teasing along with the perceived inability to defend themselves from such mistreatment. The persistent exposure to these negative behaviors as well as the perceived inability for self-defense can have serious implications for the individual's overall health.

As for the consequences of bullying at the workplace, according to (Esfahani \& Shahbazi, 2014), bullying can have harmful effects on the physical and mental health on organizational members as they can be exposed to various diseases and mental health disorders including anxiety and depression. Organizational members who are exposed to bullying at the workplace are at risk for lower self-esteem and lack of self-confidence. Moreover, they may suffer from social isolation, aggression, and depression, all of which may reduce job satisfaction and negatively affect the overall organizational performance (Bano \& Malik, 2013; Ekici \& Beder, 2014; Salin, 2015).

\subsubsection{Violence as Dysfunctional Behavior}

Violence refers to situations when employees are abused or threatened because of circumstances related to their work which can threaten their emotional well-being and physical health (Aytaç \& Dursun, 2012). Workplace violence refers to various forms of abuse, assault, or threatening behavior or aggressive attitudes at the work place. Furthermore, violence may range from verbal abuse to physical assault or murder (Kennedy et al., 2011). According to (Howard, 2001) violence refers to the illegal behavior or attitude that reduces the security of organizational members. Regarding the consequences of violence at the workplace, violence at the workplace can negatively affect both the direct victim as well as the witnesses of such violence from being exposed to such events and fearing to experience such violence themselves in the future. In turn, violence can damage employees' emotional and physical health (Aytaç \& Dursun, 2012). Moreover, violence at the workplace can affect organization overall organization performance as it can reduce productivity and job satisfaction, adding to increase absenteeism and turnover rates (Heponiemi, Kouvonen, Virtanen, Vänskä, \& Elovainio, 2014). Dillon (2012) confirms that violence can increase the likelihood of harmful physical and mental health issues such as high blood pressure, depression, or even suicide in severe cases of violence at workplace.

\subsubsection{Harassment as Dysfunctional Behavior}

According to York \& Brookhouse (1988), harassment refers to any act that may cause annoyance or frustration to another person; these acts may be as offensive sexual harassment which is motivated by a sexually intentions. Sadruddin (2013) relates the verbal or the physical harassment generally to the current situation of women in the world. According to Merkin (2009), sexual harassment is the most common type of harassment which is a form of completely unethical and humiliating conduct at the workplace. McDonald \& McDonald (2012) confirm as well that sexual harassment represents very abusive behavior that must be prevented at workplace. As for the consequences of 
harassment at the workplace, it has been studied extensively in the literature and shown to lead to damaged work-relations, reduced productivity, lower job satisfaction, lack of work motivation, and depressed morale in addition to higher turnover and absenteeism rates, which negatively affects the overall organizational performance (Swift \& Kent, 1994; York \& Brookhouse, 1988).

\subsection{Consequences of Dysfunctional Behavior}

There are various negative outcomes that can result from various forms of dysfunctional behavior at the workplace that will deteriorate the overall organizational performance (MacKenzie et al., 2015; Nehme, Mutawa, \& Jizi, 2016). According to (York \& Brookhouse, 1988), dysfunctional behavior can cause a severe level of tension, anxiety, fatigue, and stress especially harassment as leading to severe fear and anger. According to (Verkuil, Atasayi, \& Molendijk, 2015), bullying can affect mental health and well-being as being shame, lowering self-esteem, or being depressed. Unfortunately, it may lead to mental disturbance which may lead to criminal acts or (in the most severe cases) suicide (Lewis, Sheehan, \& Davies, 2008). According to (van Fleet \& van Fleet, 2012), dysfunctional behavior can reduce the overall level of employees' performance as it can prevent them to work at full capacity. Moreover, employees may lack the overall motivation to work resulting in increased levels of absenteeism and turnover rates (Sandler, 2013). Dysfunctional behavior creates an uncomfortable environment for employees that will in turn keep the deterioration of their performance (Tai, Narayanan, \& McAllister, 2012). Moreover, Baldacchino, Tabone, Agius, \& Bezzina (2016) confirmed that dysfunctional behavior will reduce the organizational commitment and employees' loyalty to the organization which will in turn affect the overall organizational performance because of higher level of absenteeism and turnover rates. According to van Fleet \& van Fleet (2012), dysfunctional behavior will reduce overall employees' job satisfaction which in turn will increase turnover and absenteeism rates as well as reduce the overall organizational performance. York \& Brookhouse (1988) sheds the light on the high cost associated with high turnover and absenteeism rates resulted from dysfunctional behavior. Moreover, dysfunctional behavior can lead to the deterioration of the organization's image and reputation especially in case of any form of harassment at the workplace as well as to the low organizational citizenship behavior and in turn the fall of the overall organizational performance (MacKenzie et al., 2015; Mahlendorf, 2015).

\subsubsection{The Negative Impact of Workplace Incivility, Bulling and Violence}

Incivility which is also referred as bullying, mobbing, emotional abuse is a form of dysfunctional behavior that causes violence, aggression and any form of deviant behavior in the work place. Incivility can be manifested in rudeness, teasing, ignoring emails phone calls or when a supervisor does not answer back his subordinate morning greetings or question or treats him with disrespect. Bulling is an escalated level of incivility at workplace that rarely involves fighting but is a form of nonphysical violence. Sexual harassment may occur in uncivil work environment resulting in sabotage (Glendinning, 2001). Bulling as a form of violence is an escalated level for work place incivility which crosses organizational gender, race and rank. Work place bullying, incivility, physical violence lies on the 10-point continuum for organizational disruption. Incivilities range from 1 to 3 , while bulling occupies 4 to 9 which is mild to severe interference. While the highest score is linked with homicide, the negative consequences from mistreated individual may regard incivility to cause little or no harm. Bullying can cause mild to severe harm while physical violence can result in death (Namie, 2003). Incivility, bulling, violence and any sort of dysfunctional behavior has been revealed to affect both employees and organizational performance.

\subsubsection{The Negative Impact on Employees}

Pearson, Andersson, \& Porath (2000) discussed that any disrespect to employees through emails, face to face communication or actions can affect employees' moral and psychology negatively. Employees who are targets of these negative behaviors my feel hurt, develop a feeling of unfairness and insecurity towards their jobs. The results of these negative feeling may last long with them developing both cognitive and affective impairment. Employees who are usually victims of incivility or dysfunctional behavior may develop depression and severe anxiety.

Employees may also develop negative psychological symptoms or will be emotionally not stable suffering from depression, sleep disorder, low self-esteem, and lack of self-confidence. Yamada (2000) revealed in his study that employees who are exposed to unfair treatment will develop negative attitude and hatred towards their employers and may intend to do any harm or practice or any sort of deviant behavior like working less or slowly, express aggression or anger. Employees experiencing workplace incivility reported stress, depression, mood swings, sleeping problems, feelings of shame, guilt, embarrassment, and low self-esteem. This negative feeling may be reflected to other coworkers who witness their colleagues' mistreatment by their supervisors and feel that that they will definitely be the next victims. Dysfunctional behavior and negative workplace may affect employees' job motivation due to a reduction in their psychological feeling of empowerment (Yamada, 2000). 


\subsubsection{The Negative Impact on Organizations}

Most studies revealed that dysfunctional behavior has very negative effect on organizational performance. Pearson et al. (2000) in their study revealed that more than third of workers reduced their effort at work intentionally, refused to do any job not written in their job descriptions. The study also revealed that the team spirit among colleagues disappeared as they stopped helping one another or the newcomers which affected organizational performance and profit drastically. Victims of these negative behaviors may withdraw from any committees, team work that inspires innovation for their organization. About 50\% claim that they will quit their jobs upon any other job opportunity that comes to them, while $12 \%$ actually quit their jobs. Subordinates of psychologically abusive supervisors were found to have higher turnover rates and negative attitude towards their jobs and their organizations at large.

Disrespectful abuse by supervisors affects their subordinates' well-being and productivity negatively. Intimidation as one of the disrespectful abuse by supervisors; may cause subordinates to lose faith and confidence in themselves. The victims of the intimidated behavior may feel helpless and restless, working hard without any autonomy given, avoid any discretion or responsibility in decision making but only follow their boss's direction to avoid being hit by them if they do any mistake.

Dysfunctional behavior can also impact the organization stakeholders as employees who are victims of these negative behaviors may blow their frustrations on customers or clients or speak about their dissatisfaction with regards to the disrespectful work environment. The negative impact of this disrespectful work behavior may result in employees intentionally not doing their best, waste lot of time at work. Absenteeism increases among employees and productivity suffers.

If these negative behaviors and attitudes are left unchecked and unsolved from the part of management, it will lead to a spiral of dysfunctional acts between supervisors and their subordinates that will undermine employees' moral, productivity, organizational performance and competitiveness (Estes \& Wang, 2008).

\subsection{Job Performance}

Job performance can be explained as the total outcome of the work carried out by employees, the level of quality involved, the time spent in it and the effort that was exerted to perform that work. Although job performance is very common to all organizations and managers set performance indicators for their employees to abide with it, but still there is no specific definition that are commonly used the literature as definitions can vary significantly. Job performance can be explained as the investment of time and effort by employees in their work place. The productivity and competitiveness of organizations depends on the extent of employees' effective and efficient job performance (Brown \& Leigh, 1996).

Brown \& Leigh (1996) discussed in their study that organizations' positive work environment helps and motivates employees to enhance their performance due to their satisfaction with their jobs. Employees' high involvement and commitment levels to their efforts, energy and time are fulfilled when they feel that the surrounding environments of their organizations are meaningful, psychologically safe; supportive and at the same time empowering them to express their views freely and share decisions.

Borman \& Motowidlo (1993) divided job performance into task and contextual performance that are required for organizational effectiveness. Task performance was defined as the effectiveness with which job incumbents perform activities that contribute to the organization's technical core. Task performance is the kind of behavior that is linked to the formal reward system of the organization. Borman \& Motowidlo (1997) also referred to the task performance as the kind of behaviors that are directly involved in producing goods or service, or activities that provide indirect support for the organization's core technical processes.

On the other hand, contextual performance was defined as performance that is not formally required as part of the job but helps shape the social and psychological context of the organization (Borman \& Motowidlo, 1993). Contextual performance according to (Werner, 2000) can be explained as the individual efforts that is important but not directly related to their main task functions. Contextual performance constitutes the organizational, social and psychological environments which serve as the critical catalyst for the task activities and process.

Van Scotter \& Motowidlo (1996) also discussed in their work that contextual performance has two components which are interpersonal facilitation and job dedication. Interpersonal facilitation includes all the behaviors and acts that help assist coworkers' activities like cooperation, consideration, and help. While job dedication, encompass all the activities and acts related to self-discipline and motivation such as working hard, initiation, and abiding by rules and regulations to support organizational objectives. Organizational effectiveness is affected by its contextual performance (Van Scotter \& Motowidlo, 1996). 


\subsection{Job Performance Measures}

\subsubsection{Determinants of Job Performance}

Addison (2005) discussed in his study that employees' job performance is positively affected by the following determinants:

- Ability: It is manifested in employee's stable skills that are used in getting a certain task done.

- Effort: It is explained in the motivation that usually triggers employee's efforts, in other words, when an employee is motivated in his work, he/she will exert much effort or energy to perform the job successfully.

- Role Perception: In order for employees to put their effort in the right place and perform efficiently, they should understand their role clearly.

- Planning: It is crucial to achieve objectives and to meet deadlines.

\subsubsection{Performance Indicators}

According to (Goodman \& Svyantek, 1999), performance indicators for employees can be identified by their managers through some criteria like:

- Achieving objectives.

- Meeting performance criteria.

- Fulfilling job requirements.

- Capability of acquiring a higher position with its more responsibilities and duties.

\subsubsection{Poor Performance Determinants}

According to Byars \& Rue (2007) poor performance can also be identified by some determinants or criteria that affects employee's performance negatively such as:

- Absenteeism and Lateness: These factors can affect employee's productivity negatively. Absenteeism is the act of not showing up to work without any prior notice for any reason. While, lateness is the act of showing up after the scheduled time or date.

- Lack of Ability/Knowledge: If the employee lacks the "Know How" to perform a particular job, he will not be able then to function or perform well due to the lack of the required skills for that job.

- Mental/Psychological Problems: Employees who are suffering from some mental or psychological problems due to stress, alcoholism or drug abuse will have negative implications on their work performance and productivity.

\section{Methodology}

\subsection{SEKEM as a Case Study}

In order to study the issue of organizational dysfunction in Egypt, a unique organization was taken for the study, namely SEKEM. SEKEM remains one of the most unique and exceptional institutions in Egypt and offers a look into how the traditional concepts of organizational dysfunction and performance may apply in such a context. What makes SEKEM unique is its focus on Sustainable Development and Human Consciousness as core guiding principles. Various different studies and cases provide a comprehensive view of the organization including (ElBedawy, Ramzy, Maher, \& Eldahan, 2017; Schieffer \& Lessem, n.d.).

\subsection{Qualitative Research Approach}

This research is qualitative research based on the approach of Action Research. Through this approach, a semi-structured interview was designed by the researchers and used to collect data from the employees of SEKEM. The study was designed as an exploratory research to determine the most common and most critical sources of dysfunction in this institution.

30 employees were interviewed in total $(n=30)$ at different levels and departments of the SEKEM organization were selected using a judgmental sampling design. The results of the interviewed were then transcribed and analyzed by the researchers.

\section{Analysis}

The analysis was conducted using a system of defining axial codes that fit the responses of the interviewees with the concepts defined in the literature review. Thus, each interview was reviewed in order to determine and select the 
comments that fit within the defined axial coding. These results were then quantified as per the number of mentions within the interview and summarized below.

\subsection{Sources of Dysfunction}

Within the semi-structured interview, respondents were asked about the sources of the organizational dysfunction within SEKEM for both themselves and their colleagues. The results of such responses are summarized in Table 1.

Table 1. Summary of responses on organizational dysfunction

\begin{tabular}{lllll}
\hline Axial Code & Problems from Colleagues & Colleague Treatment & Source of Dysfunction & Total \\
\hline Insecurities & 3 & 7 & 1 & 11 \\
Attitude & 11 & 8 & 3 & 22 \\
Turnover & 0 & 4 & 3 & 7 \\
Incivility & 4 & 3 & 3 & 10 \\
Organizational problems & 0 & 2 & 11 & 13 \\
Poor performance & 6 & 4 & 1 & 11 \\
Technical problems & 0 & 1 & 3 & 4 \\
Unfairness & 4 & 1 & 0 & 5 \\
Sexual harassment & 0 & 1 & 0 & 1 \\
Discrimination problems & 0 & 1 & 1 & 2 \\
Lack of appreciation & 1 & 0 & 3 & 4 \\
Communication problem & 2 & 1 & 8 & 3 \\
Lack of qualification & 0 & 0 & 3 & 5 \\
Financial problems & 0 & 0 & 5 & 4 \\
Job description problems & 0 & 0 & 4 & 7 \\
Management problems & 1 & 1 & 5 & 3 \\
Recruitment problems & 0 & 0 & 3 & 4 \\
Motivational problems & 3 & 0 & 1 & 3 \\
Feedback problems & 0 & 0 & 3 & 4 \\
Evaluation problems & 2 & 0 & 2 & 2 \\
Workload problems & 0 & 0 & 2 & \\
\hline
\end{tabular}

As it can be seen in Table 1, the most common form of organizational dysfunction witnessed by the interviewees were from attitude problems (22), organizational problems (13), insecurities (11), poor performance (11), \& communication problems (11). This demonstrates the wide range of sources of organizational dysfunction within the organization which highlight critical issues from the perception of the employees. One respondent summarized the sources of their problems and frustrations as follows:

"Letting personal problems affect professional work. When these issues occur, we feel moody and demotivated as well as angry about it because it affects our job negatively and thus makes us not productive. Inflexibility in procedures delays our work as each task takes too much unnecessary time to get it done. Confusion about goals in terms of not fully understanding what I should do as I can do other tasks that are irrelevant to my job description."

However, many other issues were determined to have very little relation to the organizational dysfunction. For example, only one instance of sexual harassment was mentioned and only 2 instances of discrimination. This reflects the significant amount of work placed by SEKEM in order to make the workplace a place of inclusivity for all employees.

\subsection{Impact of Dysfunction}

After asking respondents about the sources of dysfunction within SEKEM, they were then asked on how this impacted employees and their performance. The results are as follows in Figure 1. 


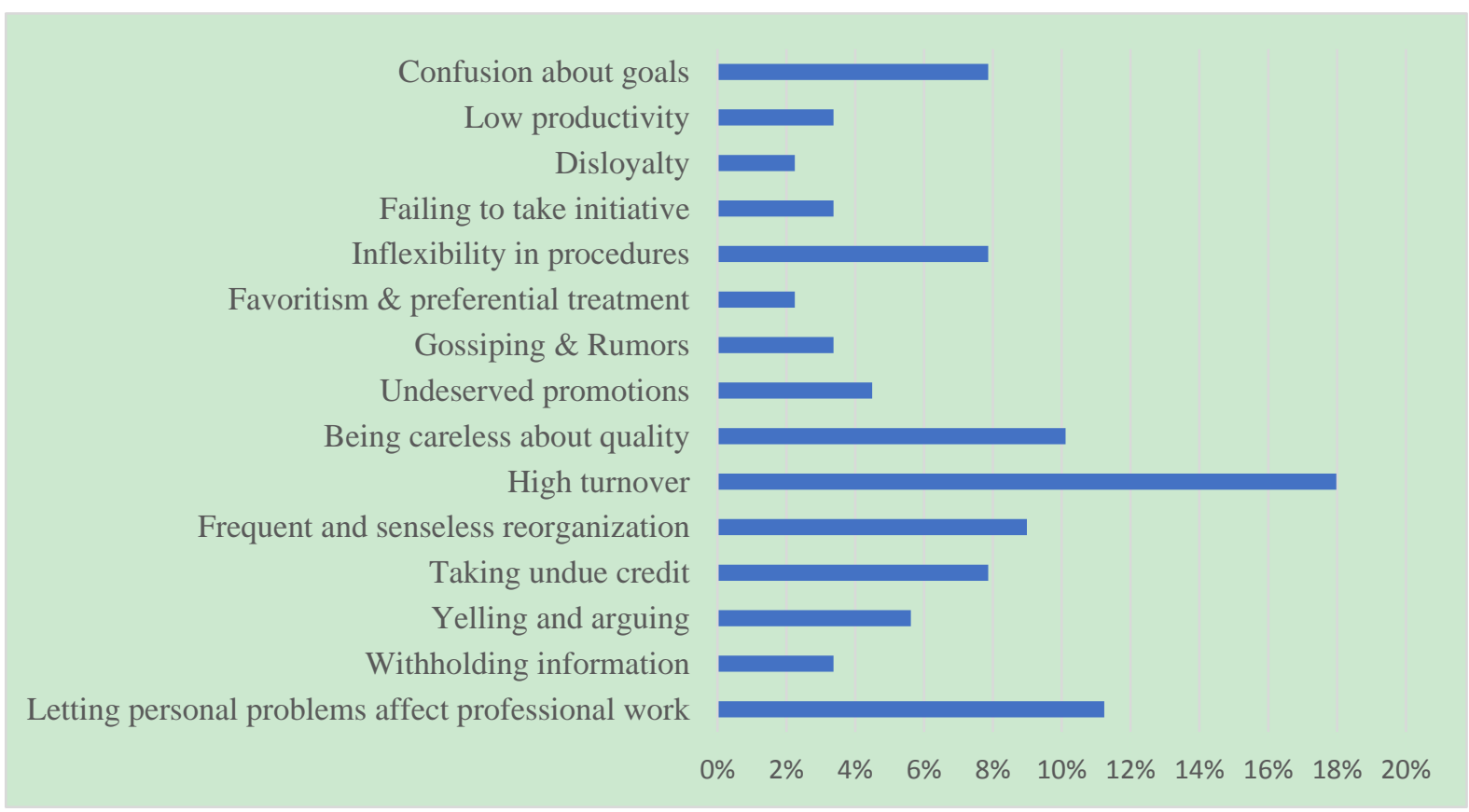

Figure 1. Impact of organizational dysfunction

As it can be seen in Figure 1, the most common problem caused by the aforementioned sources of organizational dysfunction was the high turnover rate in the institution. This was mentioned by the interviewees over $18 \%$ of the time and represents a critical source of problems for the organization. One of the respondents expanded on the turnover as a major source of frustration within the institution as follows:

"As for high turnover, it takes so much time (like 3 months) to train new employees that replace the old ones which is very exhausting."

Other impacts identified were letting personal problems affect work (11\%), being careless about quality (10\%), \& frequent and senseless reorganization (9\%).

\section{Discussion \& Recommendations}

\subsection{Discussion}

As it could be seen in the analysis, significant challenges face SEKEM from the most common sources of organizational dysfunction. However, some of the most critical and problematic sources of dysfunction (i.e. sexual harassment, discrimination, etc.) remain only minor problems within the organization. This points to the success of the efforts of SEKEM and its vision of sustainable development. However, as the organization continues to grow, more and more sources of dysfunction are appearing.

As such, SEKEM must begin to focus on more intangible sources of dysfunction such as unclear goals, inconsistencies in management, etc. Despite the fact that many of the problems are typical issues faced by companies that have grown beyond certain sizes and continue to internationalize and expand, if these issues are not addressed, these issues will begin to cause significant impediments to organizational performance in the future as well as cause for significant brain-drain on the company as a result of higher turnover rates and lower incidences of employee loyalty to the organization.

Other results of note include when respondents were asked on their belief in SEKEM and its vision, and the vast majority of respondents mentioned that the concept of sustainable development was what kept them committed to the vision of SEKEM. This should also be considered in light of the fact that the total number of times and the total percentage for each of the items remains relatively low. This presents a unique opportunity for addressing organizational dysfunction in the organization. For example, one respondent mentioned that: 
"The spirit and engagement in several events happening in the Sekem community affect the personality and perspective of persons. After spending some years in this place, the person finds himself looking at things from completely new angle and perspective."

It should also be noted that many of the issues are direct results of some of the most impressive achievements of the organization. While SEKEM's focus on cultural inclusivity and intercultural dialogue has been an incredible success, it may be directly tied to the issues of miscommunication that were mentioned by the respondents. Different languages, cultures, and contexts inevitably lead to misunderstandings.

\subsection{Recommendations}

Among the implications of the study is that the measures that are taken by SEKEM for human development has had some successes in reducing some of the more critical and aggressive forms of organizational dysfunction, yet it has still allowed for other forms to remain. As such, it is recommended that SEKEM begin to take new approaches to seriously tackle managerial issues with the same focus as it does cultural issues. As such, objectives and jobs should be made clearer, responsibilities should be made more transparent, evaluation methods should be clarified, and significant focus should be placed on improving communication issues within the organization. One recommendation provided by the respondents was as follows:

"When it comes to people leaving that we invested in them we need to hold to them, listen to their need and we don't let them leave unless they did a fatal mistake but small mistakes we have to fix it and try find solutions."

\section{Conclusion}

It is important to note that despite all of the social innovations established by SEKEM, and despite placing the human at the center of the organization, common issues of organizational dysfunction still managed to crop upon in and around the organization. Lack of clarity about goals, managerial issues, insecurities, and many other issues still purvey the entire institution of SEKEM. These points are pervasiveness of such dysfunction among people of all types and all walks of life. However, the way to address such dysfunction must be unique to SEKEM and its culture.

\section{Acknowledgment}

The contribution of Ms Mona M. Khalil, Teaching Assistant at Faculty of Business \& Economics, Heliopolis University for Sustainable Development, Egypt is well considered. Mona's dedication for helping with the data collection process is highly appreciated by the authors.

\section{References}

Addison, J.T. (2005). The determinants of firm performance: Unions, works councils, and employee involvement/high-performance work practices (IZA Discussion Paper No. 1620).

Aytaç, S., \& Dursun, S. (2012). The effect on employees of violence climate in the workplace. Work, 41, 3026-3031. https://doi.org/10.3233/WOR-2012-0559-3026

Baldacchino, P.J., Tabone, N., Agius, J., \& Bezzina, F. (2016). Organizational Culture, Personnel Characteristics and Dysfunctional Audit Behavior. The IUP Journal of Accounting Research \& Audit Practices, XV(3).

Balthazard, P.A., Cooke, R.A., \& Potter, R.E. (2006). Dysfunctional culture, dysfunctional organization: Capturing the behavioral norms that form organizational culture and drive performance. Journal of Managerial Psychology, 21(8), 709-732. https://doi.org/10.1108/02683940610713253

Bano, S., \& Malik, S. (2013). Impact of Workplace Bullying on Organizational Outcome. Pakistan Journal of Commerce \& Social Sciences, 7(3), 618-627. Retrieved from http://search.ebscohost.com/login.aspx?direct=true \&db=bth\&AN=96167571\&site=ehost-live

Borman, W.C., \& Motowidlo, S.J. (1993). Expanding the criterion domain to include elements of contextual performance. Personnel Selection in Organizations, 71-98. https://doi.org/10.1007/SpringerReference_7472

Borman, W.C., \& Motowidlo, S.J. (1997). Task Performance and Contextual Performance: The Meaning for Personnel Selection Research. Human Performance, 10(2), 99-109. https://doi.org/10.1207/s15327043hup1002_3

Branch, S., Ramsay, S., \& Barker, M. (2013). Workplace bullying, mobbing and general harassment: A review. $\begin{array}{llll}\text { International Journal of } & \text { Management }\end{array}$ https://doi.org/10.1111/j.1468-2370.2012.00339.x

Brown, S.P., \& Leigh, T.W. (1996). A new look at psychological climate and its relationship to job involvement, 
effort, and performance. Journal of Applied Psychology, 81(4), 358-368. https://doi.org/10.1037/0021-9010.81.4.358

Byars, L., \& Rue, L. (2007). Human Resource Management (9th ed.). McGraw-Hill.

Caruana, A., Ramaseshan, B., \& Ewing, M.T. (2001). Anomia and deviant behaviour in marketing: Some preliminary evidence. Journal of Managerial Psychology, 16(5), 322-338. https://doi.org/10.1108/EUM0000000005526

Cleary, M., Walter, G., Andrew, S., \& Jackson, D. (2013). Negative workplace behaviours at the University of Hard Knocks. Contemporary Nurse. https://doi.org/10.5172/conu.2013.44.2.253

Dillon, B.L. (2012). Workplace violence: Impact, causes, and prevention. Work. https://doi.org/10.3233/WOR-2012-1322

Ekici, D., \& Beder, A. (2014). The effects of workplace bullying on physicians and nurse. The Effects of Workplace Bullying on Physicians and Nurses, 31(4), 24.

ElBedawy, R., Ramzy, O., Maher, A., \& Eldahan, O.H. (2017). The Role of Training, Democratization, and Self-Actualization in Addressing Employee Burnout. International Business Research, 10(8), 93-105. https://doi.org/10.5539/ibr.v10n8p93

Esfahani, A.N., \& Shahbazi, G. (2014). Workplace bullying in nursing: The case of Azerbaijan province, Iran. Iranian Journal of Nursing and Midwifery Research, 19(4), 409-415. Retrieved from http://ijnmr.mui.ac.ir/index.php/ijnmr

Estes, B., \& Wang, J. (2008). Workplace Incivility: Impacts on Individual and Organizational Performance. Human Resource Development Review, 7, 218-240. https://doi.org/10.1177/1534484308315565

Gill, H., Meyer, J.P., Lee, K., Shin, K. H., \& Yoon, C.Y. (2011). Affective and continuance commitment and their relations with deviant workplace behaviors in Korea. Asia Pacific Journal of Management, 28(3), 595-607. https://doi.org/10.1007/s10490-009-9165-0

Glendinning, P.M. (2001). Workplace Bullying: Curing the Cancer of the American Workplace. Public Personnel Management, 30(3), 269-286. https://doi.org/10.1177/009102600103000301

Goodman, S.A., \& Svyantek, D.J. (1999). Person-Organization Fit and Contextual Performance: Do Shared Values Matter. Journal of Vocational Behavior, 55(2), 254-275. https://doi.org/10.1006/jvbe.1998.1682

Henle, C.A. (2005). Predicting Workplace Deviance from the Interaction between Organizational Justice and Personality. Journal of Managerial Issues, 17(2), 247-263.

Heponiemi, T., Kouvonen, A., Virtanen, M., Vänskä, J., \& Elovainio, M. (2014). The prospective effects of workplace violence on physicians' job satisfaction and turnover intentions: The buffering effect of job control. BMC Health Services Research, 14. https://doi.org/10.1186/1472-6963-14-19

Howard, J.L. (2001). Workplace violence in organizations: An exploratory study of organizational prevention techniques. Employee Responsibilities and Rights Journal, 13(2), 57-75. https://doi.org/10.1023/A:1014582808567

Kennedy, R.B., Burks, E., Calhoun, S., Essary, M., Herring, S., Kerner, L.L., \& Machuca, A. (2011). Workplace Violence: A Discussion and Ongoing Study. International Journal of the Academic Business World, 5(1), 40.

Lewis, D., Sheehan, M., \& Davies, C. (2008). Uncovering workplace bullying. Journal of Workplace Rights, 13(3), 281-301. https://doi.org/10.2190/WR.13.3.e

MacKenzie, C., Garavan, T.N., \& Carbery, R. (2015). Dysfunctional Behavior in Organisations: Can HRD reduce the impact of dysfunctional organizational behavior-A Review and Conceptual Model. Managerial Psychology, $16(5), 322-338$.

Mahlendorf, M.D. (2015). Allowance for failure: reducing dysfunctional behavior by innovating accountability practices. Journal of Management and Governance, 19(3), 655-686. https://doi.org/10.1007/s10997-013-9276-3

McDonald, P., \& McDonald, P. (2012). Workplace Sexual Harassment 30 Years on: A Review of the Literature, Workplace Sexual Harassment 30 Years on: A Review of the Literature. International Journal of Management Reviews, 14(1), 1-17. https://doi.org/10.1111/j.1468-2370.2011.00300.x

Merkin, R.S. (2009). South American perspectives on sexual harassment: the standpoint in Argentina, Brazil and 
Chile. Journal of Behavioral and Applied Management, 10, 357-376. Retrieved from http://gateway.library.qut.edu.au/login?url=http://proquest.umi.com/pqdweb?did=1983760881\&Fmt=7\&clientI $\mathrm{d}=14394 \& \mathrm{RQT}=309 \& \mathrm{VName}=\mathrm{PQD}$

Namie, G. (2003). Workplace bullying: Escalated incivility. Ivey Business Journal, 68(2), 1-6.

Nehme, R., Mutawa, A.Al, \& Jizi, M. (2016). Dysfunctional Behavior of External Auditors the Collision of Time Budget and Time Deadline Evidence From a Developing Country. Journal of Developing Areas, 50(1), 373-388. https://doi.org/10.1353/jda.2016.0003

Pearson, C.M., Andersson, L.M., \& Porath, C.L. (2000). Assessing and attacking workplace incivility. Organizational Dynamics, 29(2), 123-137. https://doi.org/10.1016/S0090-2616(00)00019-X

Peterson, D.K. (2002). Deviant workplace behavior and the organization's ethical climate. Journal of Business and Psychology, 17(1), 47-61. https://doi.org/10.1023/A:1016296116093

Reid, E., \& Ramarajan, L. (2016, June). Managing the high intensity workplace. Harvard Business Review, 84-90.

Rousseau, M.B., Eddleston, K.A., Patel, P.C., \& Kellermanns, F.W. (2014). Organizational Resources and Demands Influence on Workplace Bullying. Journal of Managerial Issues, 26(3), 286-313. Retrieved from http://ezproxy.aut.ac.nz/login?url=http://search.proquest.com/docview/1727963693?accountid=8440\%5Cnhttp:/ /yu7rz9hn8y.search.serialssolutions.com.ezproxy.aut.ac.nz/?ctx_ver=Z39.88-2004\&ctx_enc=info:ofi/enc:UTF8\&rfr_id=info:sid/ProQ:abiglobal\&rft_val_fmt=i

Sadruddin, M.M. (2013). Sexual Harassment at Workplace in Pakistan-Issues and Remedies about the Global Issue at Managerial Sector. Journal of Managerial Sciences, 7(1).

Salin, D. (2015). Risk factors of workplace bullying for men and women: The role of the psychosocial and physical work environment. Scandinavian Journal of Psychology, 56(1), 69-77. https://doi.org/10.1111/sjop.12169

Sandler, C. (2013). Techniques to tackle the workplace bully: Understanding the psychology and countering the behavior. Human Resource Management International Digest, 21(2), 33-36. https://doi.org/10.1108/09670731311306823

Schieffer, A., \& Lessem, R. (n.d.). Integral University Pioneer: Sekem and Heliopolis University for Sustainable Development. In Integral Development: Realising the Transformative Potential of Individuals, Organisations and Societies. Gower.

Shabrawy, S., \& Afifi, S. (2014). Seminar titled Fighting Bureaucracy and Corruption in Egypt. Supreme Council, Ministry of Culture.

Swift, C.O., \& Kent, R.L. (1994). Selling and Sales Management in Action: Sexual Harassment: Ramifications for Sales Managers. Journal of Personal Selling \& Sales Management, 14(1), 77-87.

Tai, K., Narayanan, J., \& McAllister, D.J. (2012). Envy as pain: Rethinking the nature of envy and its implications for employees and organizations. Academy of Management Review, 37(1), 107-129. https://doi.org/10.5465/amr.2009.0484

Van Fleet, D.D., \& Van Fleet, E.W. (2012). Towards a Behavioral Description of Managerial Bullying. Employee Responsibilities and Rights Journal, 24(3), 197-215. https://doi.org/10.1007/s10672-012-9190-x

Van Scotter, J.R., \& Motowidlo, S.J. (1996). Interpersonal facilitation and job dedication as separate facets of contextual performance. Journal of Applied Psychology, 81(5), 525-531. https://doi.org/10.1037/0021-9010.81.5.525

Verkuil, B., Atasayi, S., \& Molendijk, M.L. (2015). Workplace bullying and mental health: A meta-analysis on cross-sectional and longitudinal data. PLoS ONE, 10(8). https://doi.org/10.1371/journal.pone.0135225

Werner, J.M. (2000). Implications of OCB and Contextual Performance for Human Resource Management. Human Resource Management Review, 10(1), 3-24. https://doi.org/10.1016/S1053-4822(99)00036-4

Yamada, D.C. (2000). The Phenomenon of "Workplace Bullying" and the Need for Status-Blind Hostile Work Environment Protection. Georgetown Law Journal, 88(3), 475.

York, K.M., \& Brookhouse, K.J. (1988). The legal history of work-related sexual harassment and implications for employers. Employee Responsibilities and Rights Journal, 1(3), 227-237. https://doi.org/10.1007/BF01384983 